\title{
Marketing Concept in Elite Team Sports Clubs in Serbia: Impact of Leadership Styles, Organizational Learning Culture, and Climate for Innovation
}

\author{
Radenko M. Matic ${ }^{1,2}$ \\ Affiliations: 'University of Novi Sad, Faculty of Sports and Physical Education, Novi Sad, Serbia, ${ }^{2}$ Western Balkan Sport Innovation Lab, Podgorica, \\ Montenegro \\ Correspondence: R. M. Matic, University of Novi Sad, Faculty of Sport and Physical Education, Lovćenska 16, 21000 Novi Sad, Serbia. E-mail: \\ radenkomatic@uns.ac.rs
}

\begin{abstract}
This research tested the interactions among organizational learning culture, leadership styles, climate for innovation, and marketing concept of sports clubs in team sports. The study included elite sport managers $(\mathrm{N}=118)$, from four team sports (football, basketball, handball, and volleyball), who participated in the highest rank of national competition in Serbia. The organizational learning culture was measured with attitudes of respondents about the organizational learning culture at individual, team or group level, and organization as dichotomous variables, while leadership styles used the MLQ self-assessment questionnaire. The climate for innovation scale was measured with scales for assessing organizational support for creativity, maladaptation, support for innovation, and resource supply. The presence/absence of components of the different marketing mix aspects was measured as a four-dimensional variable for evaluation marketing concept. The results supported the mediation and path models. Direct effect to variable marketing concept is noticed only in the organizational learning culture, while climate for innovations and leadership style did not have a direct effect on the marketing concept. Indirect effects revealed that the status of the sports branch, the market position of each club in its sport competitive results, and the education background of managers' impact marketing concept in team sports in Serbia. The theoretical and practical contributions of obtaining results are discussed.
\end{abstract}

Keywords: organizational culture, innovation climate, sports marketing

@MJSSMontenegro

MARKETING CONCEPT IN TEAM SPORTS

http://mjssm.me/?sekcija=article\&artid=234

Cite this article: Matic, R.M. (2022). Marketing Concept in Elite Team Sports Clubs in Serbia: Impact of Leadership Styles, Organizational Learning Culture, and Climate for Innovation. Montenegrin Journal of Sports Science and Medicine, 11(1), 71-80. https://doi. org/10.26773/mjssm.220309

\section{Introduction}

A modern approach in the management of sports organizations requires the adaptation of the sports business to the tendency to quickly abandon the traditional and conservative ways of running sports organizations. This adaptation needs consistent following „puls“ of sports market with creating proactive business strategy for leading sports organizations. However, this management process is challenging because the „sports industry has a much more unpredictable nature than most other industries“ (Popovic, 2017:37). Maksimović and 
Raič (2007) see the marketing approach in solving problems in old or European sports as an essential factor in adapting such sports in a changing environment. Such changes require accepting the marketing concept and organizational innovations imposed by successful sports clubs in more developed leagues and competitions. Successful sports organizations have previously integrated these elements as crucial factors in achieving competitive and business success.

Comparison of Serbian with today's successful international sports clubs, it is evident the differences that successful organizations achieved by accepting numerous innovations in various aspects: technological, training, financial, marketing, and organizational. All this requires sports organizations to create such an external and internal environment that will enable the creation of human resources to implement the necessary changes and introduce the necessary innovations to progress.

A deeper analysis includes an evaluation of the circumstances for applying the marketing concept and an examination of the contextual factors in which the innovative changes imposed by the modern sports business are accepted or not accepted. It can be characterized as a degree of managerial support and encouragement for employees to take the initiative in their work environment that allows the organization's current capacity of all available resources. Accordingly, it is necessary to examine how leaders in Serbian sports implement organizational innovations and how favorable the climate is for their acceptance. One of the intentions of this paper is to reveal the gap between the available organizational resources of sports organizations in Serbia and the willingness of managers to accept the necessary progressive innovations. The focus of scientific research is on team sports, which can rightly be considered national sports in Serbia, which are a reflection of national pride, interest, and overall progress.

Paper aims to test the relations of an organizational learning culture, leadership styles, and climate for organizational innovations and the marketing concept in sports clubs in team sports in Serbia.

\section{Theoretical framework}

Organizational Learning Culture, Transformational Leadership, Climate for Innovation, and Marketing Concept, and Their Interrelationships

An organization that learns continuously and transforms by expanding its capacity to create its future requires a unique environment. Creating such an environment means removing obstacles to learning and encouraging and rewarding the positive work characteristics of the members of the organization (taking risks, finding a different solution to the problem, new initiatives of employees). Aware of the possibility that the combined knowledge of individuals, teams, and ultimately the entire organization, with clearly set norms of behavior of all its members, can improve the achievement of organizational goals, managers are paying more attention to creating such a business environment. A culture of learning encourages individuals and entire organizations to increase their knowledge and expertise on an ongoing basis. Further, Pasebani, Mohammadi, Yektatyar (2012) found a positive relationship between organizational learning culture and job satisfaction with internal service quality in sports organizations. On the same line, some authors emphasized the application of performance management in an elite sport where the vision and culture of sports organizations can impact athletes' performance (Armstrong, 2019; Feddersen et al., 2020).

Contemporary leadership literature relies heavily on three typologies of leadership behavior: transformational, transactional, and non-transactional laissez-faire leadership (absence of leadership). Within the framework of transformational leadership, five factors have been singled out: (1) Idealized influence (attributed), (2) Idealized influence (behavior), (3) Inspirational motivation, (4) Intellectual stimulus, (5) Individual consideration. There are two factors within transactional leadership: 6) Exception management - active, and (7) Potential reward, and two factors within non-leadership: (8) Exception management - passive and (9) fair leadership. Consequently, a growing number of researchers in this approach recommend that sports leaders be encouraged and encouraged to "train" transformational leadership. The positive impact of transformational leadership at different levels in the organization (individual, team, whole organization) was shown by Wang (2011) in a meta-analysis that states his most substantial influence at the team level. Based on that, it is possible to more efficiently realize the set business ventures, easier acceptance of the desired innovations, and adapt to change. Therefore, outstanding results can be expected from a group of people who work together with trust and complementarity and have common goals beyond individual goals. The vision of applied leadership styles across organizational learning culture is expected to contribute to progress in for-profit and non-profit sports organizations (Megheirkouni, 2017).

From the very presence of the organizational climate, it is clear that it is a vital prerequisite to consider, analyze and accept or reject the necessary organizational innovations. Therefore, it is not surprising that a growing body of research examines how organizations foster innovation and creativity and focus on the organization's individual, group, and team levels. As the essential leadership qualities, creative environment, creativity, and innovation occupy an important place in many industries, including sports. The biggest challenge for modern sports organizations is innovation and undertaking various activities for their implementation, i.e., human resources within them must find a way to turn the planned strategy into a successful result. All this requires sports organizations to create such an external and internal environment that will enable the creation of human resources to implement the necessary changes and introduce the necessary innovations to progress. Some authors state that the history or tradition of sports organizations can influence deterrence from innovative strategies (Smith \& Shilbury, 2004), and Wolfe, Wright \& Smart (2006) emphasize the importance of innovation among champions (successful clubs) who have a long tradition in professional sports contexts. The vital role of dimensions of organizational climate in the prediction of innovation in sports clubs of different levels of competition is training and innovation (Escamilla-Fajardo, Núñez-Pomar, and Parra-Camacho, 2019).

The relationship of an organizational learning culture, leadership styles, and climate for innovation are of practical and theoretical value for sports marketing and management. Findings from previous research identified several dimensions essential for defining all determinants that impact sports clubs' innovations and marketing concepts. Thus, Svensson, \& Mahoney (2020) emphasized the organizational culture, leadership, paid staff, infrastructure, and financial resources as the main contributors to social innovation in sport. 
Further, an essential role in mediation is supporting innovation (Bosselut, Guilbert, \& Chareyre, 2020), one dimension of organizational climate, which significantly influences employees' attitudes related to their achievement (Tuna, 2014). In that atmosphere for support for innovation, organizational creativity is determined from the work environment, employee social interactions, and creativity (Smith, \& Green, 2020). These authors highlighted that the sports industry could consider as unique in its approach to creativity management. Therefore, certain factors that generate a successful innovation in marketing concept, from management's point of view, can be divided into external and internal.

\section{Proposed Hypothesized Model and Study Hypotheses}

The research objectives were (1) to test if organizational learning culture, leadership styles, and climate for innovation have a direct impact on marketing concept, and (2) to examine whether relationships between characteristics of sports club and his environment and marketing concept is mediated by organizational learning culture, leadership styles and climate for innovation. As briefly discussed above, the theoretical model in Figure 1 encompasses all hypothesized dimensions (variables) and their relationships in a way that defines causeand-effect relationships that determine the variability of the dependent variable Marketing concept.

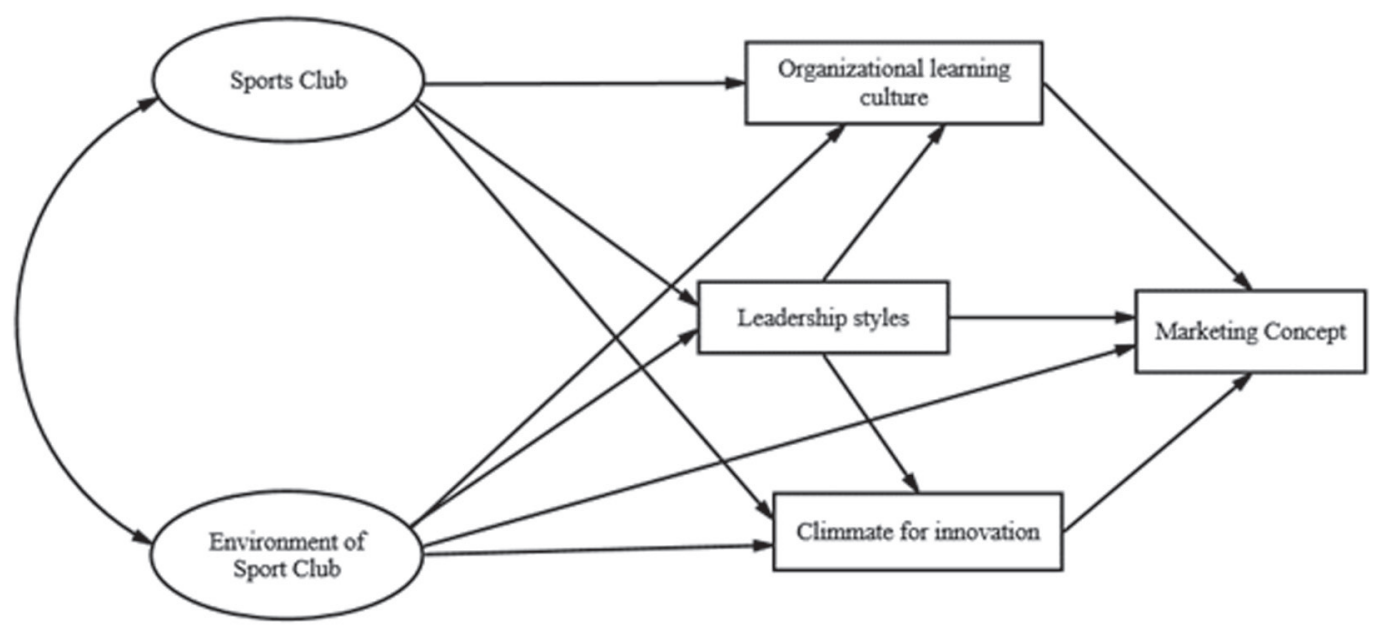

Figure 1. Proposed hypothesized model

The core of the model is the hypothesis about the conditionality of the marketing concept, the general status of marketing, and the circumstances for its application in the organization. The model is conceived on the principle of a „black box" (systems whose input and output are known, and internal connections need to be revealed - at first, they are only theoretically assumed). The entrance to the system is known, and these are the internal characteristics of the sports organization (sports branch, club type, facilities, staff, and finances) and its external environment (sponsors and the local community). The mediator dimensions in this model are organizational learning culture, leadership style, and climate for innovation. Finally, the exit from the system is known - marketing concept - as a dependent variable that measures the presence or absence of a marketing concept in a sports organization or is an indicator of sports and business success of a sports organization.

External factors for applying the marketing concept of management are sports branch, type of club, facilities, staff, finances, sponsors, local community. Inadequate resources for the application of marketing result in poor preconditions for applying its concept. From that aspect, the first and second hypothesis is related to characteristics of a sports organization and her external environment of sports organizations:

Hypothesis $1_{0}$ : The characteristics of a sports organization have no mediating effect on the marketing concept.

Hypothesis $1_{\mathrm{a}}$ : The characteristics of a sports organization have a mediating effect on the marketing concept.

Hypothesis 20 : The external environment of a sports organization has no mediating effect on the marketing concept.

Hypothesis $2 \mathrm{a}$ : The external environment of a sports or- ganization has no mediating effect on the marketing concept.

After external dimensions that affect the marketing concept, defined the following hypotheses from internal dimensions (mediators) were set:

Hypothesis $3_{0}$ : Organizational learning culture has no positive direct relationship with marketing concepts.

Hypothesis $3_{\mathrm{a}}$ : Organizational learning culture has a positive direct relationship with marketing concepts.

Hypothesis $4_{0}$ : Leadership styles have no positive direct relationship with marketing concepts.

Hypothesis $4_{a}$ : Leadership styles have a positive direct relationship with marketing concepts.

Hypothesis $5_{0}$ : Climate for innovation in sport has no positive direct relationship with marketing Concept.

Hypothesis 5 : Climate for innovation in sport has a positive direct relationship with marketing Concept.

\section{Methods}

\section{Data Collection}

The questionnaire was forwarded through national branch federations and associations to ensure the best possible research treatment in sports clubs. An additional motivation of the respondents for the most careful approach to filling in the submitted questionnaires was the opportunity to get a brief overview of the obtained results based on the research itself.

Considering that $80.5 \%$ of the respondents expressed a desire to receive feedback, i.e., a copy of the obtained results, it can be considered that there was a high motivation of the respondents to participate in the conducted research. The percentage of clubs included in the sample was $78.5 \%$ of all existing clubs in the highest rank of the competition, ie, 44 out of 56 clubs in 
all team sports. The number of clubs by sports that took part was as follows: football -12 , basketball -10 , handball -10 and volleyball - 12 clubs. Managers from 12 sports clubs in the total sample of sports clubs (21.5\%) were absent from the respondents because they did not fulfil their obligations on time and submitted the required information in the questionnaire.

\section{Study Sample}

The sample of respondents in this research consisted of 118 available managers of different levels in the organizational structure of sports organizations from four selected collective sports (football, basketball, handball, and volleyball), which institutionally belong to the highest rank of competition in Serbia (Table 1). The reason for selecting the team sports organizations is based on that these sports organizations in Serbia have been marked for decades as the most exciting and attractive to various stakeholders.

Within each sports organization-club, the following are included in the survey: (1) management representatives (president, secretary, etc.), (2) middle-level managers (marketing, finance sector, etc.), (3) professional staff representatives and leaders of the first competition teams. Namely, these are managers whose work depends on applying the marketing concept of management in sports clubs.

Table 1. Socio-demographic characteristics of the respondents

\begin{tabular}{|c|c|c|c|}
\hline & & $\mathrm{N}$ & $\%$ \\
\hline \multirow{2}{*}{ Sex } & Male & 101 & $(85,5 \%)$ \\
\hline & Female & 17 & $(14,5 \%)$ \\
\hline Age & \multicolumn{2}{|c|}{$M=43,49 S D=10,1$} & \\
\hline \multirow{4}{*}{ Nationality } & Serbian & 102 & 95,3 \\
\hline & Montenegro & 2 & 1,9 \\
\hline & Bosnian & 2 & 1,9 \\
\hline & The others & 1 & 0,9 \\
\hline \multirow{6}{*}{ Education } & Primary school & 0 & 0 \\
\hline & Secondary school & 23 & 20,0 \\
\hline & High School & 29 & 25,2 \\
\hline & Bachelor & 56 & 48,7 \\
\hline & Master & 7 & 6,1 \\
\hline & $\mathrm{PhD}$ & 0 & 0 \\
\hline \multirow{5}{*}{ Qualification } & Sports and physical education & 30 & 40,5 \\
\hline & Economy & 18 & 24,3 \\
\hline & Business / related degree & 12 & 16,2 \\
\hline & Diploma in Marketing & 12 & 16,2 \\
\hline & Certificate in marketing & 2 & 2,7 \\
\hline \multirow{6}{*}{ Ex-sport status } & Municipal & 4 & 4,9 \\
\hline & Zonal & 4 & 4,9 \\
\hline & Provincial & 11 & 13,4 \\
\hline & Republican & 33 & 40,2 \\
\hline & International in the country & 12 & 14,6 \\
\hline & International abroad & 18 & 22,0 \\
\hline \multirow{8}{*}{$\begin{array}{l}\text { Role / position in } \\
\text { management } \\
\text { club }\end{array}$} & Youth coach & 12 & 10,5 \\
\hline & First team coach & 15 & 13,2 \\
\hline & Club secretary & 27 & 23,7 \\
\hline & Chief Accountant & 0 & 0 \\
\hline & Club director & 20 & 17,5 \\
\hline & Club president & 6 & 5,3 \\
\hline & Head of Marketing Department & 7 & 6,1 \\
\hline & Some other function & 27 & 23,7 \\
\hline
\end{tabular}

\section{The Research Instruments}

Respondents, managers in sports clubs, were given the task of answering a structured questionnaire was used to measure the following variables:

Organizational learning culture was measured using 21 items with scales related to three levels of organizational learning: individual, team or group, and organization as di- chotomous variables, about whether the items are appropriate/unsuitable for a sports organization. This questionnaire for researching the organizational culture of learning in sports organizations was applied by Xie (2005).

Leadership style: To collect information on respondents 'leadership styles, an MLQ self-assessment questionnaire was developed, a form developed by Avolio \& Bass (2004) with 45 
items, with an inventory of respondents' leadership style characteristics (measured by the Likert scale with five degrees), and for its reproduction in this study, the necessary permission was obtained from the publisher Mind Garden, Inc., Menlo Park, CA USA. All scales of leadership style (transformational, transactional, and liberal behavior) have four items: Idealized Influence (attributed), Inspirational Motivation, Intellectual Stimulation, and Individualized Consideration. Transactional leadership contained the following factors: Management through exceptions (Active), Management through exceptions (Passive), Potential Reward, while within the liberal factor Lesse-fair leadership.

Climate for Innovation scale, was measured with 16 items with scales for assessing organizational support for creativity, maladaptation, support for innovation, and resource supply as measured by the Likert scale with 5 degrees. This inventory was proposed by Saross, Gray, Densten, Parry, Hartican, Cooper (2005) based on a survey of leadership, organizational climate, and innovation in Australian organizations.

The variable Finance has calculated the difference between total net gains and total net losses.

The marketing concept of sports organizations is a four-dimensional variable that is constituted based on the obtained results on the presence/absence of components of the marketing concept: (1) human resources, (2) financial resources, (3) content of sports offer (organizational), (4) conditions of sports facility where the club plays matches (training-technological), which were measured by the Likert scale with 5 degrees. It is understood that the relationships within the system are such relationships that affect the variation of the output variable of the Marketing concept, i.e. that its values are $0=$ there is no application of the marketing concept or 1 $=$ there is a Marketing concept - depending on the connection of dimensions (represented by extracted/sieved and composite variables). Accordingly, all sports clubs are classified in one of 16 defined categories.

\section{Data analysis}

The statistical analysis of the research included several phases:

Firstly, an a reliability test was performed for each questionnaire segment separately. After that, the calculation of basic descriptive statistics for all variables by questionnaire segments. Further, the final stage of the analysis consisted of performing: Path-analysis, where the whole procedure was performed in AMOS, version 21.0 - as its dedicated statistical and graphical solution. Full model coefficients (arrows) from a series of layered multiple regression analyses (path coefficients are beta coefficients from regression analysis) help create an empirically based picture of the factors that determine the research phenomenon or marketing concept. It can be stated that this is a saturated model whose reduction based on tests of empirical variables should establish a model that best shows the situational, real data obtained by surveys in sports clubs. The process of accepting all dimensions required implementation of the fitting model of empirical data passed through several fit indices: Root Mean Square Error of Approximation (RMSEA), Comparative Fit Index (CFI), and the Non-Normed Fit Index (NNFI). Subsequently, internal fit indices with factor loadings and the inter-item reliability of the constructs above were carried out using Cronbach's alpha, Composite Reliability (CR), and Average Variance Extracted (AVE) according to $\mathrm{Hu}$, \& Bentler (1999).

The reduction of factors that explains the marketing concept is achieved based on the principle of parsimony (simplification). This model is a macro-model of research and based on it, using several submodels, direct, indirect, and total effects between all observed variables in the model were examined. To better understand the functioning of the mechanisms of action between the components within the starting points of the marketing concept, this research used an approach that involved the analysis of mediation. Mediation analysis (according to Judd \& Kenny, 1981; Baron \& Kenny, 1986) - to better understand the functioning of the mechanisms of action between components within an empirical research model.

Two models for analysis were prepared: 1) model for mediation analysis, and 2) model for path-analysis. The first model was supposed to show the details of the connection and the effects - from which all the strong, credible connections were seen. The second model - reduced based on the results of the first stage, showed how the attitude of clubs towards the acceptance of the marketing concept is formed.

\section{Results}

The obtained results of reliability test $(\alpha)$ by segments are as follows: Leadership Questionnaire, $\alpha=0.84$; Organizational learning culture, $\alpha=0.87$; Climate for organizational innovation, $\alpha=0.84$; Sports marketing, $\alpha=0.97$. These values are acceptable $(>0.75)$, suggested recommendations by Nunnally and Bernstein (1994).

Variables that meet the normality requirements and the conditions necessary for performing multivariate statistical

Table 2. Descriptive variable sample statistics

\begin{tabular}{|c|c|c|c|c|c|c|}
\hline & Min & Max & Mean & SD & Sk & $\mathrm{Ku}$ \\
\hline Sports branch & 1 & 4 & 2.40 & 1.17 & 0.16 & -1.46 \\
\hline Educational background & 2 & 5 & 3.42 & 0.87 & -0.36 & -0.82 \\
\hline Assets & 1 & 3 & 2.25 & 0.76 & -0.44 & -1.14 \\
\hline Club type & 1 & 9 & 5.43 & 3.17 & -0.21 & -1.60 \\
\hline Finance & 0.00 & 13.01 & 6.88 & 3.33 & -0.49 & -0.37 \\
\hline Place & 1.00 & 26.00 & 5.23 & 6.22 & 1.85 & 2.59 \\
\hline Sponsor & 1 & 2 & 1.81 & 0.39 & -1.56 & 0.44 \\
\hline Leadership style & 1 & 5 & 3.71 & 1.28 & -0.73 & -0.63 \\
\hline Learning culture & 0 & 1 & 0.76 & 0.26 & -1.10 & 0.72 \\
\hline Innovation & 2.18 & 4.75 & 3.42 & 0.51 & 0.07 & -0.38 \\
\hline Marketing concept & 1.00 & 2.00 & 1.52 & 0.50 & -0.10 & -2.02 \\
\hline
\end{tabular}


analyses (path-analyzes) were selected. The state of coverage of the multivariate analysis model has been met (at least 10 cases/ respondents per model element - the initial theoretical model has 11 components, and the sample has 118 respondents).

Before starting the path analysis procedure, a gradual reduction of the complex initial empirical model was undertaken to obtain an optimal model appropriate to the requirement of parsimony (simplicity) that allows testing the set research hypothesis. By successive omissions from the model of tracks with a low value of beta coefficients, starting with the value less than 0.01 , over the value less than 0.05 to the value less than 0.10 , a total of 19 tracks were omitted.

To more fully understand the direct and indirect effects of variables entered in the saturated model, the mediation analysis of all submodels of the initial model was undertaken before concluding the correlations and effects in the reduced model. The submodels were formulated by relating two paths of direct effects - one variable from the club construct ( 5 variables in total) and one from the environment construct (2 variables in total) - thus obtaining ten direct effects submodels. In the end, $10+60$ submodels were obtained, a total of 70 submodels were tested using mediation analysis (according to Kenny, for the application of Amos for mediation analysis). Using the four-step method, 12 submodels with total mediation and 18 submodels were extracted from the 60 mediation submodels shown above. In the identified submodels with partial mediation, an additional application of the Sobel test of the significance of paths with partial mediation was performed. Given the practical importance of partial mediation, the analysis focuses on the submodels of partial mediation. Applying the above mediation analysis procedure to all 18 submodels of partial mediation, the following conclusions were drawn:

- Medium partial mediation with a significant mediation effect $(Z>1.96)$ was priced on the Sponsor - Innovation Marketing concept.

- Weak partial mediation with a significant mediation effect $(Z>1.96)$ was found on the paths: Place - Innovation - Marketing concept and Human Resources - Learning Culture - Marketing concept.

- Stronger partial mediation without a significant mediation effect $(Z<1.96)$ is found only on the Sponsor - Leadership style - Marketing concept path.

- Other paths are characterized by weak partial mediation without significant mediation effect $(Z<1.96)$ (two paths are weak and unreliable partial mediation).

- Variables - constructs of style and innovation appear as mediators on 8 tracks, while the construct of cult appears on only two paths.

This insight suggests the inclusion in further path-analysis of independent variables from the latent variable sponsor environment and location and personnel from the latent variable club. As mediators, they deserve attention primarily from innovation, then the leadership style, while the mediator variable learning culture, with its lower frequency of involvement in mediation effects, deserves attention as an additional factor. Insight into complete mediation (Table 3) points to an important characteristic of three exogenous variables: primarily the variables finance and the variables assets from the latent variable club and place from the latent variable environment, pushing the three mediator variables from the role of independent variables.
The second stage of path-analysis requires reliance on the reduced empirical model. The direct effects of the four exogenous factors that operate in the long run are primarily the status of the club, its affiliation to a particular sport, its type in terms of competitive placement, and staffing. Assets, measured by the disposition of assets and financial results, have a slight direct effect. The indirect effect of the club environment is manifested through the sponsor effect, while the wider local community environment does not have a significant effect.

The analysis of indirect effects through three mediator variables shows that the situation of clubs in specific sports and on the scale of competitive success plays a key role in the reception of the marketing concept in the observed sample of clubs. The effect of the club type on the reception of the marketing concept through the culture of learning is shown most fully thanks to the independence of this mediator concerning the management style of club management and weak susceptibility to the effect of club sponsors. The effects of both exogenous factors on learning culture, as the most influential mediator in the reception of the marketing concept, have a negative effect. With the rise of the club on the competition ladder and the acquisition of sponsors, the learning culture shows a declining trend. This result represents a certain illogicality.

The second, more complex channel of indirect effects on the acceptance and application of the marketing concept in the observed clubs is mediated by the innovative climate in club management. This climate is subject to the direct effects of the club's affiliation to a particular sport and the mediating role of the club leadership style, and the effect of the established culture of organizational learning. The effect of innovation on the reception of the marketing concept in these clubs is weak and lags behind the learning culture. Innovations are oriented towards technical, and to a lesser extent, organizational and marketing capacities of the club. Leadership style does not directly affect the adoption of the marketing concept in clubs. This mediating factor acts in isolation from most exogenous factors and is more strongly associated with the affiliation of clubs to specific sports. The leadership style of the club management is oriented towards innovations, primarily technical (training methods, equipment, etc.). This style is an essential factor in initiating an innovation climate in cooperation with changing the type of club (achieving competitive results) and the property teaming of the sports organization.

The previous statements about the strength and type of mediation were made without completely determining the significance of all paths in the reduced model. By applying the bootstrapping analysis method, a complete picture of the significance of all paths that make up the analyzed path model was obtained. Based on the results of bootstrapping analysis, it can be stated the existence of full mediation on the path of the key-> innovation (significance of the indirect effect $\mathrm{p}<0.05$ and at the same time the significance of the direct effect $\mathrm{p}>0.05$ ).

The absence of mediation was found for all variables entered in the model, except for the paths leading from the variable button to innovation and marketing concept (except for paths for which some of the forms of mediation were previously determined). Identification of statistically significant pathways and types of mediation in a reduced model (bootstrap analysis) is shown in Tables 3,4 , and 5. 
Table 3. No mediation

\begin{tabular}{|c|c|c|c|c|c|c|c|c|c|}
\hline & $\mathrm{P}$ & $\mathrm{S}$ & $\mathrm{TC}$ & SB & LS & LC & EB & $A$ & I \\
\hline Leadership styles & $\cdots$ & $\cdots$ & $\cdots$ & $\cdots$ & $\cdots$ & $\cdots$ & $\cdots$ & $\cdots$ & $\ldots$ \\
\hline Learning culture & $\cdots$ & $\ldots$ & $\ldots$ & $\cdots$ & $\ldots$ & $\ldots$ & $\ldots$ & $\cdots$ & $\ldots$ \\
\hline Innovation & 0.11 & 0.11 & 0.00 & 0.09 & $\ldots$ & $\ldots$ & $\ldots$ & $\cdots$ & $\ldots$ \\
\hline Marketing concept & 0.38 & 0.11 & 0.00 & 0.40 & 0.37 & 0.32 & 0.55 & 0.40 & $\ldots$ \\
\hline
\end{tabular}

Note. P - Place, S - Sponsor, TC - Type of club, SB - Sports branch, LS - leadership styles, LC - Learning culture, EB - Educational Background, A - Assets, I - Innovation, Indirect Effects p > 0.05 - Two Tailed Significance.

Due to full mediation (Table 4), the role of the Type of club $\rightarrow$ Innovation path is taken over by the Type of club - Learning culture path, whose successor is the Learning culture $\rightarrow$ Marketing concept path, which affects the criterion variable Marketing concept. This analysis confirms the significance of the effect of partial mediation on the paths Type of club $\rightarrow$ Learning culture, Type of club -> Innovations, Learning culture $\rightarrow$ Innovations, as well as on the paths of direct effects with the criterion variable Sponsor-> Marketing concept,
Sports branch $\longrightarrow$ Marketing concept, Learning culture $\rightarrow$ Marketing concept and Educational background -> Marketing concept.

The previous analysis showed that the insufficient strength of connection and unsystematic mediator factors represent a limitation in the work of management in the effort to apply the marketing concept in clubs. The unconnectedness of the learning culture with the climate of innovation is a bottleneck in the marketing reconstruction of club management.

Table 4. Full mediation

\begin{tabular}{cccccccccc}
\hline & $\mathrm{P}$ & $\mathrm{S}$ & $\mathrm{TC}$ & $\mathrm{SB}$ & $\mathrm{LS}$ & $\mathrm{LC}$ & $\mathrm{EB}$ & $\mathrm{A}$ & $\mathrm{I}$ \\
\hline Leadership styles & 0.03 & $\ldots$ & $\ldots$ & 0.00 & $\ldots$ & $\ldots$ & $\ldots$ & $\ldots$ & $\ldots$ \\
Learning culture & $\ldots$ & 0.11 & 0.00 & $\ldots$ & $\ldots$ & $\ldots$ & $\ldots$ & $\ldots$ & $\ldots$ \\
Innovation & $\ldots$ & $\ldots$ & 0.05 & 0.04 & 0.09 & 0.00 & 0.40 & 0.09 & $\ldots$ \\
Marketing concept & $\ldots$ & 0.00 & 0.00 & 0.00 & $\ldots$ & 0.00 & 0.00 & 0.16 & 0.32 \\
\hline
\end{tabular}

Note. P - Place, S - Sponsor, TC - Type of club, SB - Sports branch, LS - leadership styles, LC - Learning culture, EB Educational Background, A - Assets, I - Innovation, Direct effects $p>0.05$ and Indirect effects $p<0.05$ - Direct Effects - Two Tailed Significance, $\mathrm{X} 2=864,56, \mathrm{df}=214, \mathrm{X} 2 / \mathrm{df}=4.04, \mathrm{CFI}=0.93, \mathrm{NFI}=0.92, \mathrm{RMSEA}=0.06$.

Partial mediation (Table 5) was found on the paths: Place - Leadership style, Type of club $\rightarrow$ Learning culture, Type of club $\rightarrow$ Innovations, Learning culture $\rightarrow$ Innovations, as well as on the paths of direct effects that establish variables Sponsor, Sports branch, Learning culture and Educational background with the criterion variable Marketing concept.

Table 5. Partial mediation

\begin{tabular}{cccccccccc}
\hline & $\mathrm{P}$ & $\mathrm{S}$ & $\mathrm{TC}$ & $\mathrm{SB}$ & $\mathrm{LS}$ & $\mathrm{LC}$ & $\mathrm{EB}$ & $\mathrm{A}$ & I \\
\hline Leadership styles & 0.03 & $\ldots$ & $\ldots$ & 0.00 & $\ldots$ & $\ldots$ & $\ldots$ & $\ldots$ & $\ldots$ \\
Learning culture & $\ldots$ & 0.11 & 0.00 & $\ldots$ & $\ldots$ & $\ldots$ & $\ldots$ & $\ldots$ & $\ldots$ \\
Innovation & 0.11 & 0.11 & 0.00 & 0.13 & 0.09 & 0.00 & 0.40 & 0.09 & $\ldots$ \\
Marketing concept & 0.38 & 0.00 & 0.15 & 0.00 & 0.37 & 0.00 & 0.00 & 0.20 & 0.32 \\
\hline
\end{tabular}

Note. P - Place, S - Sponsor, TC - Type of club, SB - Sports branch, LS - leadership styles, LC - Learning culture, EB - Educational Background, A - Assets, I - Innovation., Total Effects - p $<0.05$ - Two - Tailed Significance.

\section{Discussion}

Based on the applied statistical procedures, the null hypothesis $\mathrm{H} 0$ was tested, followed by the alternative hypotheses $\mathrm{Ha}$ (direct connections and indirect connections). The obtained results confirmed that: There are statistically significant correlations between the dependent variable and certain defined factors in the empirical research model, thus rejecting the basic null hypothesis. About alternative hypotheses, it has been shown that there are direct and indirect connections.

Effects on the dependent variable marketing concept were determined in 4 exogenous and 1 mediator variables. Of the indirect effects of the exogenous factor characteristics of the sports club, the following existed: club status, sports branch, type of club, and educational background (which supports H1a). Assets and financial results (balance) have a slightly indirect effect. It is noticeable that the weak financial status of sports organizations excludes its effect on the marketing con- cept. Such results according to the parameters for assessing the financial sustainability of sports organizations proposed by Foster, Greyser \& Walsh (2006) indicate the weaknesses of domestic sports organizations in the following 6 factors: 1) Strength of the league to which clubs belong, 2) Club brand and its history and tradition, 4) Stadium where the club hosts matches, 5) City or area where the club is located and 6) Owner characteristics and club culture. Observing the following parameters, it can be concluded that the clubs rely heavily on the history and tradition of the club but that the implementation of their branding is lacking.

Numerous researches have confirmed the connection between the sports competition result with motivation and spectators' identification with the team. Various studies have as their starting point to investigate the motivational factors of individuals who are willing to invest financial, emotional, and time resources in watching and watching sporting events 
(James \& Ridinger, 2002; Milne \& McDonald, 1999; Wann, 1995). The necessity of identification with successful teams imposes the achievement of consistently good sports results. Namely, the audience is looking for confirmation of good competitiveness in the international competition with clubs, and accordingly, during the season, there is the most significant interest in international matches. Knowing this causal connection, the clubs try to achieve notable results in the domestic competition at any cost to be placed in the international rankings of the competition, which has a stimulating effect on the entire organization. Sports organizations in Serbia must "shape" the sports offer on the market as soon as possible, which will be as competitive as possible at the regional and international level, and accordingly attract the attention of the domestic audience.

In terms of manager education, it is certain that educated managers better understand the needs of innovation and are ready for a higher degree of necessary adjustments. Mumford (2000) and Kearney, Feldman, \& Scavo (2000) emphasize the need for education in the process of diffusion of innovation because new ideas and solutions require the knowledge and expertise of employees. Also, Maksimović and Raič (2012) emphasize the high share of staff in the development of services in sports, which makes staff education an important factor in marketing strategy (mix).

In addition to education, Damanpour \& Schneider (2008) show that managerial and personal characteristics influence adaptation to innovation rather than demographic characteristics, while (Borins, 2000) shows that entrepreneurs with an entrepreneurial orientation see innovation as a need for change.

As for the Environment, as another exogenous factor, the indirect effect is manifested through the sponsor effect, while the wider environment (local community) has no significant impact. Therefore, H2a is partially supported).

Of the mediator variables, the only direct effect is present in the learning culture (which supports H3a). These relationships are consistent with research conducted by Williams (2010), which showed that organizational culture is associated with business success. The author cites adaptability, strong culture, vision, and employee participation as key aspects of a successful organizational culture. In general, based on the overall results of all respondents' individual, group, and organizational learning culture, it can be considered that a good organizational culture is "nurtured" in domestic clubs. However, if we look at the climate for organizational innovation, which relies heavily on organizational culture, it is noticeable that there are bigger problems with it. The weakest results concern the maladaptation factor, where over $40 \%$ of respondents point to a low level in this climate factor for organizational innovation.

This factor in the sports organization implies a climate where employees have many problems if they think and work differently and do not respect the orders received. Also, the significant problem is that many respondents see the highest degree of agreement with others as a very influential way to progress in their work environment, which indicates problems in expressing differences concerning the ruling attitudes. Certainly, a climate with as many like-minded people as possible is not desirable for implementing various innovations and creative ideas. The next problem in this segment is the unsatisfactory level of resources available to sports organizations.
Regarding other mediator variables, the following was determined: (1) Leadership style did not have a direct impact on the adoption of the marketing concept in clubs, and (2), Innovations did not have a direct effect on the Marketing concept which means that $\mathrm{H} 4 \mathrm{a}$ and $\mathrm{H} 5 \mathrm{a}$ are rejected. These results agree with the results of research conducted using a questionnaire based on the Hersey-Blanchard situational approach to leadership Jurak and Bednarik (2010). The obtained results led the authors to conclude that the leadership of Slovenian sports organizations is generally "blind" in terms of the importance of leadership in this context.

As budgets and human resources are often reduced in sports organizations and where leaders often need to do more with fewer resources, the ability of management to transform or inspire individuals to act in the best interests of the organization is vital. Herrera and Lim (2003) emphasize the essential importance of transformational leadership for success in sports clubs. The key factors of the "right" style of leadership in sports organizations, according to the results obtained by Maksimovic, Milosevic, Matic, and Obradovic (2011), are: (1) Specific factors that are specific to the sports organization, (2) Factors that are specific to leaders in the goal encouraging motivational needs and work expectations of employees, (3) Personal and reference factors typical of different leadership styles include the key skills, sensitivity, reasonableness, and flexibility in working with people.

With the change of innovation in the club, a mediation path is being established for clubs in sports already open to marketing influences. The mentioned intervention in the orientation of the innovation climate in the club is also contributed by the type of club in terms of its competitive orientation (Type of club) and the use of property potential that can be put in the function of marketing business performance of the club (Assets). However, it should be taken into account that the price of innovation negatively affects the adjustment by employees, so that less expensive innovations are more accepted by organizations (Rogers, 2003; Damanpour, \& Schneider, 2008).

A potential limitation of the work is the application of an abbreviated form of the MLQ 5X questionnaire for self-assessment of leadership behavior by managers. More comprehensive information would be obtained by applying the second part, which refers to the form of evaluation of leaders by others. Nevertheless, the information obtained in this form of the questionnaire represents the personal perception of leadership behavior, based on which the idea of leaders' beliefs about their leadership is gained. The absence of a form of evaluation of leaders by followers in the organization was considered a practical approach, since the problem of this paper is not to examine the differences between leadership vision, on the one hand, and evaluation of their leadership by subordinates, but the perception of managers in sports organizations concerning organizational culture and marketing concept. The obtained results represent the "picture" of the leadership of current managers in our sports clubs from the group of team sports.

Considering that the obtained results represent the evaluation of the management of sports organizations concerning the current sports offer provided by our sports clubs in collective sports, it should be borne in mind that on this occasion the opinions of consumers and spectators of sports events of these clubs were missing. Additionally, each of the segments in future research (especially the sponsor's factor, the local en- 
vironment) may be covered by additional information about these phenomena. In this way, in addition to the anticipated elements of the theoretical model, it should be monitored whether there are certain modifications in the results obtained with additional effects on the sports organization of the media, clients/consumers, and other stakeholders. The space for future research is opened by the application of the experimental approach, which is almost absent in domestic research.

In general, it can be stated that the analysis of indirect effects shows that the interpretation of the Marketing concept should take into account the importance of indirect effects of the competitive type of club on innovation and learning culture, innovation, and learning culture, and places Leadership style. The results of the analysis of the partial mediation submodels show that they existed with different strengths on these paths: Weak - (1) Place $\rightarrow$ Innovation $\rightarrow$ Marketing concept. Such connections indicate that innovations are very much determined by the location where the clubs are located, which, as expected, indicates an indirect effect on the marketing concept. This shows in sports practice that innovations are not equally widespread in all clubs and that the marketing concept depends on the local environment in which it is implemented; (2) Human resources $\rightarrow$ Learning culture $\rightarrow$ Marketing concept. The connection of organizational culture with the educational capacity of the sports organization shows that the acquired education to some extent determines the "creation" of organizational culture through which its connection with the application of the marketing concept is further established. (3) Medium - Sponsor $\rightarrow$ Innovation $\rightarrow$ Marketing concept.

The expected connection that indicates that the implementation of innovations depends on the presence of sponsors, which allow improving the resources necessary for the functioning of the marketing concept. Accordingly, it can be stated that in addition to the direct effect on the marketing concept, sponsorship also acts indirectly through the creation of a more favorable climate that is more willing to accept the necessary progressive innovations.

\section{References}

Armstrong, R. (2019). Critical realism and performance measurement and management: Addressing challenges for knowledge creation. Management Research Review, 42(5), 568-585. https://doi.org/10.1108/MRR-05-2018-0202

Avolio B.J., \& Bass B.M. (2004). Multifactor Leadership Questionnaire. Manual and sampler set. (3rd ed.) Redwood City, CA: Mind Garden.

Baron, R. M., \& Kenny, D. A. (1986). The moderator-mediator variable distinction in social psychological research: Conceptual, strategic and statistical considerations. Journal of Personality and Social Psychology, 51(6), 11731182. https://doi.org/10.1037//0022-3514.51.6.1173

Borins, S. (2000). Loose cannons and rule breakers, or enterprising leaders? Some evidence about innovative public managers. Public Administration Review 60(6), 498-507. https://doi.org/10.1111/0033-3352.00113

Bosselut, G., Guilbert, L., \& Chareyre, L. (2020). Transformational leadership and creativity in sport: Examining the mediating role of support for innovation. Journal of Sports Sciences, 38(23), 2698-2707. https://doi.or g/10.1080/02640414.2020.1796186.

Damanpour, F., \& Schneider, M. (2008). Characteristics of Innovation and Innovation Adoption in Public
Organizations: Assessing the Role of Managers. Journal of Public Administration Research and Theory, 19(3), 495-522.

Escamilla-Fajardo, P., Núñez-Pomar, J. \& Parra-Camacho, D. (2019). Does the organizational climate predict the innovation in sports clubs? Journal of Entrepreneurship and Public Policy, 8(1), 103-121. https://doi.org/10.1108/ JEPP-03-2019-104.

Feddersen, N. B., Morris, R., Littlewood, M. A., \& Richardson, D. J. (2020). The emergence and perpetuation of a destructive culture in an elite sport in the United Kingdom. Sport in Society, 23(6), 1004-1022. https://doi.org/10.1080 /17430437.2019.1680639.

Foster, G., Greyser, P. and Walsh, B. (2006). The Business of Sports: Texts and Cases on Strategy and Management. London: Thomson South-Western.

Herrera, R., \& Lim, J. (2003). Job satisfaction among athletic trainers in NCAA division Iaa institutions. The Sport Journal, 24(1), 1-7.

Hu, L, \& Bentler, P.M. (1999). Cutoff Criteria for Fit Indexes in Covariance Structure Analysis: Conventional Criteria versus New Alternatives. Structural Equation Modeling, 6(1), 1-55.

James, J. D., \& Ridinger, L. L. (2002). Female and male sport fans: A comparison of sport consumption motives. Journal of Sport Behavior, 25(3), 260.

Judd, C. M., \& Kenny, D. A. (1981). Process analysis: Estimating mediation in treatment evaluations. Evaluation Review, 5(5), 602-619.

Jurak, G., Bednarik, J. (2010). Leadership in non-governmental sports organisations in Slovenia. Acta Universitatis Palackianae Olomucensis, Gymnica, 40(4), 41-51.

Kearney, R. C., Feldman, B. M., \& Scavo, C. P. F. (2000). Reinventing government: City manager attitudes and actions. Public Administration Review, 60(6), 535-47.

Maksimovic, N., Milosevic, Z., Matic, R., \& Obradovic, B. (2011). Leadership styles of executives in team sports. In: M. Mikalacki \& G. Bala (eds.). $2^{\text {nd }}$ International Scientific Conference „Exercise and quality of life“, 24-26.03.2011. (445-449). Novi Sad: Faculty of Sport and Physical Education.

Maksimović, N., Raič, A. (2007). Marketing u sportu. [Marketing in sport]. XIV Medunarodni interdisciplinarni simpozijum „Ekologija, sport, fizička aktivnost $i$ zdravlje mladih", 394-400. Novi Sad: Maraton.

Maksimović, N., Raič, A. (2012). Sportski menadžment. [Sport Management]. Novi Sad: Fakultet sporta i fizičkog vaspitanja.

Megheirkouni, M. (2017). Leadership styles and organizational learning in UK for-profit and non-profit sports organizations. International Journal of Organizational Analysis, 25(4), 596-612. https://doi.org/10.1108/IJOA-072016-1042

Milne, G.R., \& McDonald, M.A. (1999). Sport marketing: Managing the exchange process. Sudbury, MA: Jones and Bartlett Publishers.

Mumford, M. D., Zaccaro, S. J., Connelly, M. S. \& Marks, M. A. (2000). Leadership skills: conclusions and future directions. Leadership Quarterly, 11(1), 155-170.

Nunnally, J.C., \& Bernstein, I. H. (1994). Psychometric theory (3rd ed.). New York, NY: McGraw-Hill.

Pasebani, F., Mohammadi, S., Yektatyar, M. (2012). The relationship between organizational learning culture 
and job satisfaction and Internal service quality in sport organizations in Iran. Archives of Applied Science Research, 4(4), 1901-1905.

Popovic, Stevo. (2017). Contemporary Sports Product and Making a Brand. Exercise and Quality of Life, 9(1), 37-41. 10.31382/eqol.170605.

Rogers, E. M. (2003). Diffusion of innovations (5th ed.). New York: Free Press.

Sarros, J. C., Gray, J., Densten, I., Parry, K., Hartican, A., \& Cooper, B. (2005). The Australian leadership survey 3: Leadership, organizational culture and innovation of Australian enterprises. Retrieved September 12, 2021 , from http://www.aim.com.au/research/ABLS_report.pdf

Smith, A., \& Shilbury, D. (2004). Mapping cultural dimensions in Australian sporting organizations. Sport Management Review, 7(2), 133-165.

Smith, N.L., Green, B.C. (2020). Examining the factors influencing organizational creativity in professional sport organizations. Sport Management Review, 23(5), 992-1004 https://doi.org/10.1016/j.smr.2020.02.003

Svensson, P. G., \& Mahoney, T. Q. (2020). Intraorganizational conditions for social innovation in sport for development and peace. Managing Sport and Leisure, 25(3), 220-238. https://doi.org/10.1080/23750472.2020.1727358

Tuna, B. (2014). The influence of person-organization fit on contextual performance and its impact on organizational effectiveness: The moderating role of organizational climate. Doctoral Dissertation, Yeditepe University Institute of Social Sciences, Istanbul.

Wang, G., Oh, S., Courtright, S. H., \& Colbert A. E. (2011). Transformational leadership and performance across criteria and levels: A meta-analytic review of 25 years of research. Group \& Organization Management, 36(2), 223 270.

Wann, D. L. (1995), Preliminary Validation of the Sport Motivation Scale. Journal of Sport and Social Issues, 19(1), 377-97.

Williams C. (2010). Principi Menadžmenta. [Principles of Management] Beograd: Data status.

Wolfe, R., Wright, P. M., Smart, D. L. (2006). Radical HRM innovation and competitive advantage: The Moneyball story. Human Resource Management, 45(1), 111-145.

Xie, D. (2005). Exploring organizational learning culture, job satisfaction, motivation to learn, organizational commitment, and internal service quality in a sport organization. PhD dissertation, Ohio State University. 